NASA/TM-2004-212659

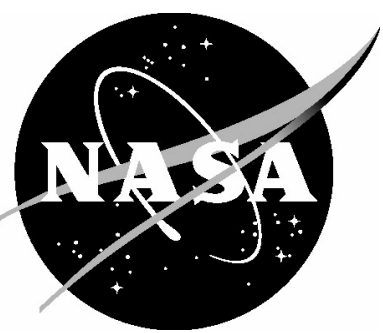

\title{
Shell Buckling Design Criteria Based on Manufacturing Imperfection Signatures
}

Mark W. Hilburger, Michael P. Nemeth, and James H. Starnes, Jr.

Langley Research Center, Hampton, Virginia 
Since its founding, NASA has been dedicated to the advancement of aeronautics and space science. The NASA Scientific and Technical Information (STI) Program Office plays a key part in helping NASA maintain this important role.

The NASA STI Program Office is operated by Langley Research Center, the lead center for NASA's scientific and technical information. The NASA STI Program Office provides access to the NASA STI Database, the largest collection of aeronautical and space science STI in the world. The Program Office is also NASA's institutional mechanism for disseminating the results of its research and development activities. These results are published by NASA in the NASA STI Report Series, which includes the following report types:

- TECHNICAL PUBLICATION. Reports of completed research or a major significant phase of research that present the results of NASA programs and include extensive data or theoretical analysis. Includes compilations of significant scientific and technical data and information deemed to be of continuing reference value. NASA counterpart of peerreviewed formal professional papers, but having less stringent limitations on manuscript length and extent of graphic presentations.

- TECHNICAL MEMORANDUM. Scientific and technical findings that are preliminary or of specialized interest, e.g., quick release reports, working papers, and bibliographies that contain minimal annotation. Does not contain extensive analysis.

- CONTRACTOR REPORT. Scientific and technical findings by NASA-sponsored contractors and grantees.
- CONFERENCE PUBLICATION. Collected papers from scientific and technical conferences, symposia, seminars, or other meetings sponsored or co-sponsored by NASA.

- SPECIAL PUBLICATION. Scientific, technical, or historical information from NASA programs, projects, and missions, often concerned with subjects having substantial public interest.

- TECHNICAL TRANSLATION. Englishlanguage translations of foreign scientific and technical material pertinent to NASA's mission.

Specialized services that complement the STI Program Office's diverse offerings include creating custom thesauri, building customized databases, organizing and publishing research results ... even providing videos.

For more information about the NASA STI Program Office, see the following:

- Access the NASA STI Program Home Page at http://www.sti.nasa.gov

- E-mail your question via the Internet to help@sti.nasa.gov

- Fax your question to the NASA STI Help Desk at (301) 621-0134

- Phone the NASA STI Help Desk at (301) 621-0390

- Write to:

NASA STI Help Desk NASA Center for AeroSpace Information 7121 Standard Drive Hanover, MD 21076-1320 
NASA/TM-2004-212659

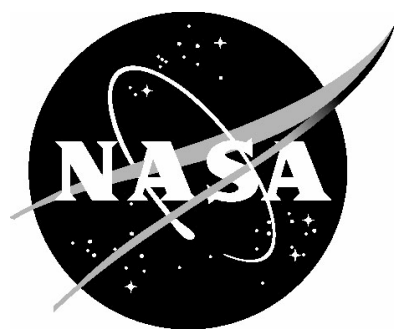

\section{Shell Buckling Design Criteria Based on Manufacturing Imperfection Signatures}

Mark W. Hilburger, Michael P. Nemeth, and James H. Starnes, Jr.

Langley Research Center, Hampton, Virginia

National Aeronautics and

Space Administration

Langley Research Center

Hampton, Virginia 23681-2199

May 2004 
Available from:

NASA Center for AeroSpace Information (CASI)

7121 Standard Drive

Hanover, MD 21076-1320

(301) 621-0390
National Technical Information Service (NTIS) 5285 Port Royal Road Springfield, VA 22161-2171

(703) 605-6000 


\begin{abstract}
An analysis-based approach for developing shell-buckling design criteria for laminated-composite cylindrical shells that accurately accounts for the effects of initial geometric imperfections is presented. With this approach, measured initial geometric imperfection data from six graphite-epoxy shells are used to determine a manufacturing-process-specific imperfection signature for these shells. This imperfection signature is then used as input into nonlinear finite-element analyses. The imperfection signature represents a "first-approximation" mean imperfection shape that is suitable for developing preliminary-design data. Comparisons of test data and analytical results obtained by using several different imperfection shapes are presented for selected shells. Overall, the results indicate that the analysis-based approach presented for developing reliable preliminary-design criteria has the potential to provide improved, less conservative buckling-load estimates, and to reduce the weight and cost of developing buckling-resistant shell structures.
\end{abstract}

\title{
Introduction
}

High-performance aerospace shell structures are inherently thin walled because of weight and performance considerations and are often subjected to destabilizing loads. In addition, fiber-reinforced composite materials are becoming more common in aerospace vehicle structures because of their high strength, high stiffness, and amenability to structural tailoring that permits design solutions that are not possible with metals. Thus, buckling is an important and often critical consideration in the design of these structures and reliable, validated design criteria for thin-walled shells are needed, especially for shells made of advanced composite materials.

As one might expect, shell-buckling design criteria have a history steeped in empiricism. ${ }^{1,2}$ From approximately 1930 to 1967, many shell-buckling experiments were conducted on metallic shells. Typically, the experiments yielded buckling loads that were substantially lower than the corresponding analytical predictions, which were based on simplified linear bifurcation analyses of geometrically perfect shells with nominal dimensions and idealized support conditions. The seminal works by von Kármán and $\mathrm{Tsien}^{3}$, by Donnell and $\mathrm{Wan}^{4}$, and by Koiter ${ }^{5}$ identified small deviations from the idealized geometry of a shell, known as initial geometric imperfections, as a primary source of discrepancy between corresponding analytical predictions and experimental results. However, it appears that because of the intense computational requirements of the nonlinear analyses used by von Kármán and Tsien and by Donnell and Wan, and the asymptotic analyses used by Koiter, at that time, buckling design allowables were determined by establishing lower bounds to test data. Specifically, empirical factors, that have become known as "knockdown" factors, were determined and were to be used in conjunction with linear bifurcation analyses for simply supported shells; that is, these empirical factors were used to "knockdown" the unconservative analytical prediction. This approach to shell buckling design remains prominent in industry practice, as evidenced by the extensive use of the NASA space vehicle design criteria. ${ }^{6-8}$

From approximately 1960 to 1989, digital computers emerged and matured as a practical tool for scientists and engineers. With these computational tools, considerable effort was put forth to determine analytically the effects of initial geometric imperfections on the buckling response of shells. These efforts were largely based on Koiter's asymptotic theory ${ }^{1,5,9}$ for idealized structural shapes with nominal dimensions and also included investigations of shells made of fiber-reinforced composite materials. ${ }^{10-13}$ In addi- 
tion, in-depth, substantial experimental investigations that focused on fiber-reinforced composite shells were conducted at institutions such as the NASA Langley Research Center and the Wright Aeronautical Laboratories at Wright-Patterson Air Force Base, in addition to various academic institutions worldwide. It was during this time period that the measurement of initial geometric imperfections in test specimens and high-fidelity response measurement techniques and apparatus were recognized as important elements in the development of design criteria for buckling of shells. ${ }^{14-17}$

Another significant development that occurred in parallel to the maturation of digital computers in the 1960s to 1980s was the development of computational structural analysis codes based on finite-difference or finite-element methods. Two prominent examples that stimulated the development of this particular technology are the NASA Structural Analysis code $\left(\right.$ NASTRAN $\left.^{18}\right)$ and the Structural Analysis of General Shells code $\left(\mathrm{STAGS}^{19}\right.$ ), which were funded by the United States government. The successors and inheritors of these codes now possess robust static and dynamic nonlinear analysis capabilities, along with extensive graphics capabilities, that enable scientists and engineers to model and visualize experiments or actual flight hardware to an enormous level of detail. Archetypal examples of the application of these tools are the in-depth, highly detailed studies of cylinder buckling response documented in Refs. 20-22 and the comprehensive and highly detailed nonlinear and buckling analyses of the Space Shuttle superlightweight external fuel tank that is documented in Refs. 23-27. In addition, the extension of these analysis techniques and codes to other disciplines has helped to enable the development of advanced experimentalresponse measurement systems. Thus, the tools and understanding now exist for developing high-fidelity shell buckling design criteria for shells of general shape and material composition and for combined mechanical and thermal loads.

Recent advances and recommendations for the development of modern shell-buckling design criteria have been given in Refs. 28 and 29. These references examine the potential benefits of adopting probabilistic and hybrid probabilistic-deterministic approaches for developing design criteria. An important concept that is discussed in Ref. 29 and used in the present study is the establishment of characteristic imperfection signatures that are associated with the different shell-manufacturing processes. This concept is based on the idea that each manufacturing process will yield shells that possess essentially similar initial geometric imperfection shapes, with a well-defined range of pointwise amplitudes. With this information established, high-fidelity analyses and selective structural testing can be used to determine refined, reliable design criteria for shell buckling that are not overly conservative like the present lower-bound approach found in NASA SP $8007 .{ }^{6}$ To this end, some effort has been put toward defining initial geometric imperfection models to be used in shell analysis for isotropic and composite shells. ${ }^{30,31}$ Similarly, various probability-based analysis methods have been proposed to develop reliable design buckling loads for imperfect shells in which approximations to the measured imperfections are used in the analyses. ${ }^{32,33}$

The present study focuses on the development of a refined shell-buckling preliminary-design criteria that is based on high-fidelity nonlinear finite-element analyses that include the effects of a manufacturingprocess-specific geometric imperfection signature. Refined preliminary-design data are important because they substantially reduce the chance of getting "locked-in" to a poor design early in a vehicledevelopment program and, in the context of stability-critical thin-walled shell structures, can give a more accurate preliminary prediction of the load-carrying capacity of the shell. One main objective of the present study is to establish a "first-approximation" characteristic imperfection signature for selected circular cylindrical shells made of a graphite-epoxy material that can be used to develop data suitable for preliminary design. Another main objective is to develop and validate an analysis-based shell-buckling design criteria that accurately accounts for the effects of initial geometric imperfections by using the imperfection signature defined herein. The final objective is to show the potential improvements in buckling predictions that can be realized, particularly for combined loading conditions. Towards these objectives, six graphite-epoxy shells with different shell-wall laminates that were previously tested and 
analyzed are discussed first. Then, the nonlinear shell-analysis procedure that is used to predict the buckling and nonlinear response of the shells is described. Next, the details of how measured geometric imperfections for six laminated graphite-epoxy shells are used to determine a manufacturing imperfection signature are presented. Then, analysis results and experimental results for selected compression-loaded shells are compared to validate the new high-fidelity analysis-based procedure for developing design criteria. Finally, numerically predicted buckling interaction curves are presented for three different shells subjected to combined axial compression and torsion to illustrate the potential benefits of the new procedure.

\section{Test Specimens, Imperfection Measurements, and Tests}

Six test specimens used in the present study are described in this section. These specimens were previously fabricated and tested at the NASA Langley Research Center in support of a research program to study the effects of initial imperfections on the nonlinear response and buckling of compression-loaded composite shells. Much of this work has been documented in Refs. 20-22 and selected details about the test specimens, imperfection measurements, and tests are summarized in this section. Additional details on the cylinder tests can be found in these references.

\section{Test Specimens}

The specimens were fabricated from 12-in-wide, 0.005-in-thick AS4/3502 unidirectional graphiteepoxy tape material. The nominal unidirectional lamina properties of a typical 0.005 -in-thick ply with a fiber volume fraction of 0.62 are as follows: longitudinal modulus $\mathrm{E}_{1}=18.5 \mathrm{Msi}$, transverse modulus $\mathrm{E}_{2}=$ $1.64 \mathrm{Msi}$, in-plane shear modulus $\mathrm{G}_{12}=0.87 \mathrm{Msi}$, and major Poisson's ratio $v_{12}=0.30$. The material was laid up by hand on a 15.75-in-diameter mandrel and vacuum bagged and cured in an autoclave to form six shells with different shell-wall laminates. These shells include shells with an 8-ply axially stiff $\left[\mp 45 / 0_{2}\right]_{\mathrm{s}}$ laminate, an 8-ply circumferentially stiff $\left[\mp 45 / 90_{2}\right]_{\mathrm{s}}$ laminate, an 8-ply quasi-isotropic [ $\left.\mp 45 / 0 / 90\right]_{\mathrm{s}}$ laminate, a 16-ply axially stiff $\left[\bar{\uparrow} 45 / 0_{2}\right]_{2 s}$ laminate, a 16-ply circumferentially stiff $\left[\overline{+} 45 / 90_{2}\right]_{2 s}$ laminate, and a 16-ply quasi-isotropic $[\overline{+} 45 / 0 / 90]_{2 \mathrm{~s}}$ laminate. These six shells are referred to herein as shells or specimens C1 through C6, respectively. These specimens had a nominal length of $16.0 \mathrm{in}$. and a nominal radius of $8.0 \mathrm{in.}$ The 8-ply and 16-ply specimens had a nominal shell-wall thickness of $0.04 \mathrm{in}$. and 0.08 in., respectively, and had shell-radius-to-thickness ratios of 200 and 100, respectively. Both ends of the specimens were potted in an aluminum-filled epoxy resin to ensure that the ends of the specimen did not fail prematurely during the test. The potting material extended approximately 1.0 inch along the length of the specimens at each end, resulting in a test section that is approximately $14.0 \mathrm{in}$. long. The ends of the specimens were machined flat and parallel to facilitate proper load introduction during the tests. A photograph of a typical test specimen and the specimen coordinate system used to represent the corresponding geometry is shown in Fig. 1. The nominal cylinder length, test-section length, radius, and thickness are designated as $L, L_{t}, R$, and $t$, respectively.

\section{Imperfection Measurements}

Three-dimensional surveys of the inner shell-wall surface of the specimens were made prior to testing to determine the initial geometric shell-wall imperfection shape. Measurements were taken over a uniform grid with increments of $0.125 \mathrm{in}$. in the axial direction and $0.139 \mathrm{in}$. (approximately $1 \mathrm{deg}$ of arc) in the circumferential direction over the exposed surfaces of the specimens. A typical contour plot of the normalized initial geometric shell-wall mid-surface imperfections $\bar{w}_{o}(x, \theta) \quad$ for specimen C3 is shown in Fig. 2. The measured shell-wall imperfection $w_{o}$ is normalized by the nominal shell-wall thickness $t_{\text {nom }}=0.04$ inches. These results indicate that the initial geometric shell-wall imperfection is periodic in the circum- 
ferential direction and exhibits slight variations in the axial direction. The amplitude of the imperfection varies from $+1.27 t_{\text {nom }}$ to $-1.536 t_{\text {nom }}$.

\section{Test Apparatus and Tests}

The specimens were instrumented with electrical-resistance strain gages and direct-current differential transducers (DCDT's) were used to measure displacements. Three non-colinear DCDT's were positioned in three corners of the upper loading platen and used to measure the end-shortening displacement and the platen rotations. A shadow moiré interferometry technique was used to observe the shell-wall prebuckling, buckling and postbuckling radial deformation patterns. All data were recorded with a data acquisition system, and the moiré patterns were recorded photographically, on videotape, and with a high-speed digital video camera.

The specimens were loaded in compression with a 120-Kip hydraulic universal-testing machine by applying an end-shortening displacement to the shell ends. To control the load introduction into the specimen, the upper loading platen was aligned with the loading surface of the specimen before the test by adjusting leveling bolts in the corners of the upper loading platen until strains measured by selected strain gages on the specimens indicated a uniform axial strain distribution in the shell wall. The specimens were loaded until global collapse of the shells occurred.

\section{Finite-Element Models and Analyses}

The finite-element models and analysis methods used in the present study are based on experimentally validated models presented Refs. 21-22. In particular, the results presented in these references indicate that highly accurate buckling responses can be predicted for compression-loaded shells if initial geometric imperfections, material property variability, nonuniform thickness distribution, and other features are modelled to a high degree of accuracy. Such validated models that include the effects of these details are generally deemed necessary to develop the most accurate, analysis-based, high-fidelity design criteria. In line with the objectives of the current study, only the effects of the initial geometric imperfection are included in the numerical models. However, the model details, such as the mesh refinement and idealized boundary conditions, and the analysis methods are the same as those used in the previous studies and, as a result, the solutions are expected to be converged. In addition, the validated finite-element models used for compression-loaded shells are also used for the analysis of the torsion-loaded shells and the shells subjected to combined torsion and compression presented herein, and are expected to be converged because of the finite-element models extensive refinement. Additional details on the finite-element models and analysis procedures are found in Refs. 21 and 22.

\section{Finite-Element Models}

The shells considered in this study were analyzed with the STAGS (STructural Analysis of General Shells) nonlinear shell-analysis code. ${ }^{19}$ STAGS is a finite-element code developed for the static and dynamic analysis of general shells, and includes the effects of geometric and material nonlinearities in the analysis. A typical finite-element model of a specimen is illustrated in Fig. 1. The standard 410 quadrilateral element from the STAGS element library was used in the models which is a flat facet-type element that is based on the Kirchoff-Love shell hypothesis and the nonlinear Lagrangian strain tensor. The element nodes include three translational degrees of freedom and three rotational degrees of freedom. Large element rotations are accounted for by using a corotational algorithm. Typically, the elements of the finite-element mesh are approximately 0.2 -in. by 0.2 -in. square. However, some of the elements near the 
boundary region of the shell are somewhat smaller in order to accurately represent the bending boundarylayer response near the end of the shell. Each element possesses four integration points, which are distributed in such a way as to provide a modeling resolution of approximately 0.1 -in. by 0.1 -in square. This integration-point spacing is on the order of the measurement-point spacing used when measuring the initial geometric imperfections of the specimens.

Compression-loaded shells and shells subjected to combined axial compression and torsion are analyzed in the present investigation. To simulate the constraints provided by the potting material in a compression-loaded shell, the circumferential and radial displacements $v$ and $w$ were set equal to zero in edge regions of the shell as indicated in Fig. 1. Similarly, for shells subjected to combined axial compression and torsion, the radial displacement $w$ was set equal to zero and the circumferential displacement $v$ was applied to simulate a torsion load.

Geometrically perfect and imperfect shells were analyzed in the present investigation. Nominal shell geometry, laminate thickness and lamina mechanical properties were used for the finite-element models for the geometrically perfect shells. The finite-element model of the geometrically perfect shells were modified to include the effects of various geometric imperfection shapes. In particular, linear-bifurcationmode imperfections, measured shell-wall geometric imperfections, and simulated initial geometric imperfections based on a "first approximation" manufacturing imperfection signature were considered. The various initial geometric shell-wall mid-surface imperfection shapes were included in the finite-element models by introducing an initial out-of-plane perturbation to each node of the mesh. A typical finite-element model contained approximately 130,000 degrees of freedom.

\section{Nonlinear Analysis Procedure}

The STAGS finite-element analysis code uses both the modified and full Newton methods for its nonlinear solution algorithms. The Riks pseudo arc-length path-following method ${ }^{34}$ is used to continue a solution past the limit points of a nonlinear response. With this strategy, the incrementally applied loading parameter is replaced by an arc-length along the solution path, which is then used as the independent loading parameter. The arc-length increments are automatically adjusted by the program as a function of the solution behavior. The transient-analysis option in STAGS uses proportional structural damping and an implicit numerical time-integration method developed by Park. ${ }^{35}$ Mass and stiffness damping factors are used in the proportional structural damping and are defined as $\alpha=2 \pi \nu \zeta$, and $\beta=\zeta / 2 \pi \nu$, respectively, where $\zeta$ denotes the fraction of critical damping and is assumed to equal 0.15 for the shells considered herein. It is assumed that the dynamic buckling response of a shell is dominated by a particular frequency of vibration, $v$, and is defined as the critical frequency of vibration determined from a linear vibration analysis in STAGS. These assumed damping parameters generally result in a slightly underdamped structural response during the transient analysis. Additional information on the transient analysis procedure can be found in Ref. 36.

The prebuckling, buckling and postbuckling responses of the shells were determined by using the following analysis procedure. The prebuckling responses were determined by using the geometrically nonlinear quasi-static analysis capability in STAGS. The Riks pseudo arc-length path-following method in STAGS was used to compute the initial shell response until just before buckling occurred. The unstable buckling response of a shell was predicted by using the nonlinear, transient-analysis option of the code. The transient analysis was initiated from an unstable equilibrium state close to the limit point by incrementing the end displacement by a small amount. An initial time step of $1.0^{-8}$ seconds was used in the analysis, and the time step was automatically adjusted by the program as a function of the solution behavior. The transient analysis was continued until the kinetic energy in the shell had dissipated to a negligible 
level, which indicated that the transient response had attenuated. Once the transient analysis had attenuated to a near-steady-state solution, the load-relaxation option of the code was used to establish the stable static equilibrium state. Results from conventional linear bifurcation buckling analyses were also determined with STAGS for comparison with the nonlinear response results.

\section{Manufacturing Imperfection Signature}

Shell-wall geometric imperfections that had been measured previously (see Refs. 20-22) for the six laminated-composite shells considered herein were used to identify a manufacturing-process-specific "first approximation" imperfection signature for this type of structure. First, a reference or "best-fit" cylinder for the initial imperfection measurement data for each shell was determined. Specifically, a data reduction program that uses the method of least squares was used to compute the rigid-body translations and rotations and the mean radius of each cylinder. Then, the measured radial imperfections, deviations from a perfect cylinder, were recalculated with respect to the corresponding new best-fit cylinder. The measured imperfection data was then represented by a two-dimensional half-wave Fourier cosine series given by

$$
w_{o}(x, \theta)=t_{n o m} \sum_{k=0}^{N} \sum_{l=0}^{N} \cos \left(\frac{k \pi x}{L}\right)\left(A_{k l} \cos \left(\frac{l \pi x}{L}\right)+B_{k l} \sin (l \pi \theta)\right)
$$

where $R, L$, and $t_{\text {nom }}$ are the shell radius, length and wall thickness; $x$ and $\theta$ are the axial and circumferential coordinates; and $k$ and $l$ are integers denoting the number of axial half-waves and circumferential full-waves, respectively. Using a standard representation of this type for the measured imperfection enables convenient analysis and comparison of different imperfection distributions from different shells and different manufacturing processes. For example, a plot of the coefficient distribution of a half-wave Fourier cosine representation of the measured geometric imperfection shape for shell specimen $\mathrm{C} 3$ is presented in Fig. 3. The results indicate that the largest-magnitude component of the imperfection is the $k=$ 0 and $l=2$ component and that the magnitudes of the other components decrease rapidly as the wave numbers $k$ and $l$ increase. The $k=0$ and $l=2$ component corresponds to a cylinder with an elliptical cross-section that has a magnitude of $1.2 t_{\text {nom }}$. The next largest component is associated with $k=1$ and $l$ $=2$ and has a magnitude of approximately $0.2 t_{n o m}$. In general, the dominant coefficients are associated with the long wave-length imperfections in the circumferential and axial directions. Coefficients for values of $k$ and $l>10$ have a negligible effect on the overall imperfection shape. However, the short wavelength components are retained in the imperfection model since these modes may be associated with high imperfection sensitivity for the shells considered herein even though their magnitudes are generally very small. ${ }^{37}$ Results for shells C1, C2, and C4-C6 indicate similar coefficient distributions and suggest that a manufacturing-process-specific imperfection signature for graphite-epoxy laminated-composite shells can be established in terms of a characteristic Fourier coefficient distribution and range. To this end, a mean imperfection shape and a corresponding standard deviation to the imperfection shape were determined based on the measured imperfection data. The mathematical expectation or mean value of $w_{o}(x, \theta)$ is given by

$$
\mu_{w}(x, \theta)=\left\langle w_{o}(x, \theta)\right\rangle=t_{n o m} \sum_{k=0}^{N} \sum_{l=0}^{N} \cos \left(\frac{k \pi x}{L}\right)\left(\left\langle A_{k l}\right\rangle \cos \left(\frac{l \pi x}{L}\right)+\left\langle B_{k l}\right\rangle \sin (l \pi \theta)\right)
$$

where $\langle\ldots\rangle$ denotes the mean value. A contour plot of the normalized mean geometric imperfections $\mu_{w}(x, \theta)$ is shown in Fig. 4. The mean shell-wall imperfection $\mu_{w}$ is normalized by the nominal shell-wall thickness $t_{\text {nom }}=0.04$ inches. These results indicate that the initial geometric shell-wall imperfection is periodic in the circumferential direction, exhibits slight variations in the axial direction, and is similar in character to the measured imperfection shape for shell C3 shown in Fig. 2. The amplitude of the imperfec- 
tion $\mu_{w}$ varies from $+1.77 t_{n o m}$ to $-1.65 t_{n o m}$. The corresponding standard deviation of the geometric imperfection shape $\sigma_{w}(x, \theta)$ is defined by

$$
\sigma_{w}^{2}\left(w_{o}(x, \theta)\right)=\left\langle\left(w_{o}(x, \theta)-\left\langle w_{o}(x, \theta)\right\rangle\right)^{2}\right\rangle
$$

A contour plot of the corresponding normalized standard deviation of the geometric imperfection shape is shown in Fig. 5. The results indicate that the maximum standard deviation is equal to $2.172 t_{\text {nom }}$ and is primarily associated with long wave-length components of the imperfection shape. In addition, the coefficient of variation was calculated for each component of the imperfection and gives the relationship between the mean and the standard deviation. The coefficient of variation, denoted by $V$, is given by

$$
V=\frac{\sigma\left(X_{k}\right)}{\mu\left(X_{k l}\right)}
$$

where

$$
X_{k l}=\sqrt{A_{k l}^{2}+B_{k l}^{2}}
$$

A typical plot of $V$ for an axial half-wave number $k=0$ is shown in Fig. 6 . The results indicate that $V$ is relatively high for long wave-length imperfections; e.g., $V=1.6$ for $k=0$ and $l=2$, and decreases rapidly to a value of approximately 0.5 for $l<20$. Results for the other values of $k$ were also obtained and indicate similar trends. This information suggests that an approximate expression that relates the mean coefficient values with the corresponding standard deviation can be developed. For example, an approximate $V$ relationship for this particular case that is applicable for all values of $k$ is given by

$$
V=\left\{\begin{array}{l}
1.25-\frac{.75}{20} l ; 0 \leq l \leq 20 \\
0.5 ; 20 \leq l \leq 50
\end{array}\right.
$$

This equation is used in subsequent sections when defining "simulated" imperfections in place of the exact standard deviation function given in Eq. 3 to simplify the calculations.

\section{Response of Compression-Loaded Shells}

The effects of five different imperfection shapes on the response of the three compression-loaded 8ply shells C1-C3 were investigated in the current study. Specifically, the effects of actual measured shellwall imperfections, simulated imperfections that are based on the "first approximation" imperfection signature, and linear-bifurcation-mode imperfections were analyzed. The simulated "first approximation" imperfection signature includes the mean imperfection with and without plus or minus one standard deviation. Load-shortening response curves and shell deformations are presented subsequently for the quasiisotropic shell C3 that illustrate the overall response characteristics for the compression-loaded shell with the five different imperfection shapes. In addition, predicted buckling loads for the two orthotropic 8-ply shells $\mathrm{C} 1$ and $\mathrm{C} 2$ with the five different imperfection shapes are also presented. Moreover, the predicted buckling loads are compared to the actual experimental buckling loads and to the design load one would get by extrapolating the results in NASA SP-8007 for isotropic shells to the composite shells.

Four predicted load-shortening response curves are presented for shell $\mathrm{C} 3$ in Fig. 7a and include results for a shell with the actual measured imperfection shape; a shell with the mean imperfection shape, 
denoted by $\mu_{\mathrm{w}}$; a shell with the mean imperfection shape plus one standard deviation, denoted by $\mu_{\mathrm{w}}+\sigma_{\mathrm{w}}$; and a shell with the mean imperfection shape minus one standard deviation, denoted by $\mu_{\mathrm{w}}-\sigma_{\mathrm{w}}$. The axial load $\mathrm{P}$ and end-shortening $\Delta$ are normalized with respect to the linear bifurcation buckling load of the geometrically perfect nominal shell, $\mathrm{P}_{\text {bif }}=42,590 \mathrm{lbf}$, and the nominal shell-wall thickness, $t_{\text {nom }}=0.04 \mathrm{in}$, respectively. The load-end-shortening curves clearly indicate a linear prebuckling response. The general instability occurs in the shell at normalized axial load levels that range from $\mathrm{P} / \mathrm{P}_{\mathrm{bif}}=0.855$, for a shell with $\mu_{\mathrm{w}}+\sigma_{\mathrm{w}}$ imperfection shape, to 0.943 for the shell with a $\mu_{\mathrm{w}}-\sigma_{\mathrm{w}}$ imperfection shape. The predicted buckling loads are summarized in Table 1. The general-instability response of the shell is followed by a sudden reduction in the axial load supported by the shell that is associated with the transient collapse response of the shell. The results indicate that the postbuckling load level is insensitive to the different types of imperfections considered herein. The corresponding load-time history of the transient collapse response of shell $\mathrm{C} 3$ with the actual measured imperfections are shown in Fig. 7b. The load-time history curve exhibits a sudden reduction in axial load until the collapse response attenuates and the axial load achieves a steady-state value. The kinetic energy in the shell obtains a maximum value during the transient collapse response and dissipates over time and the shell reaches a stable postbuckling equilibrium state after approximately 0.007-0.008 seconds. The shell exhibits postbuckling load-carrying capacity, however, the effective axial stiffness of the specimen is significantly reduced in the postbuckling range of loading, as indicated by the large reduction in the slope of the load-shortening response curves. This reduction in effective axial stiffness is caused by large-magnitude radial deformations that develop in the specimen during buckling which result in significant load redistribution in the specimen and reduce the effective, load-carrying cross-section of the cylinder.

The transient deformation responses for selected time steps during the transient collapse response of shell $\mathrm{C} 3$ with the actual measured imperfection, indicated by the letters A through D in Fig. $7 \mathrm{~b}$, are presented in Fig. 8a through 8d, respectively. Just before buckling occurs, the shell wall deformations are characterized by several localized ellipse-like buckles, as indicated in Fig. 8a. The localization in the deformation pattern is caused by the combination of a local geometric shell-wall imperfection that is in the form of a significant variation in the shell-wall geometry and the bending boundary-layer deformations that form near the end of the shell. In addition, the localized deformations occur in regions with destabilizing compressive axial and circumferential stresses. The coupling of these destabilizing stresses and the local deformations cause the buckling response in the shell. After approximately 0.0012 seconds have elapsed in the transient response, a single ellipse-like buckle has grown in amplitude and couples with the destabilizing stresses in the shell wall to cause the general instability and collapse of the shell. The magnitude of the shell-wall radial displacement varies between $\pm 0.5 t_{\text {nom. }}$. After additional time has elapsed in the transient collapse response, additional local buckles have formed around the circumference and along the length of the shell, as indicated in Fig. 8c, and the normalized axial load has decreased from 0.890 to 0.554. In addition, some of the buckles in the shell begin to coalesce into larger diamond-shaped buckles. The magnitude of the shell-wall radial displacement varies between $+3 t_{\text {nom }}$ to $-7 t_{\text {nom }}$. After approximately 0.01 seconds have elapsed in the transient response, the kinetic energy in the shell has dissipated to a negligible level indicating that the transient response has attenuated, and the shell has deformed into a stable postbuckling mode-shape, as indicated in Fig. 8d. As loading continues in postbuckling region, the diamond-shaped buckles increase in size and the magnitude of the radial deformations of the buckles and the outer-surface ridges increase to between $+4 t_{\text {nom }}$ and $-9 t_{\text {nom }}$.

Deformation results were obtained for shell C3 with the mean imperfection shape, the $\mu_{\mathrm{w}}+\sigma_{\mathrm{w}}$ imperfection shape, and $\mu_{\mathrm{w}}-\sigma_{\mathrm{w}}$ imperfection shape and indicated similar response characteristics to those exhibited by the shell with the actual measured imperfection. In particular, predicted initial buckling deformations for shell C3 are presented in Figs. 9a through 9c. These results indicate that the initial buckling deformation response of a shell with the mean imperfection $\mu_{\mathrm{w}}$ and the $\mu_{\mathrm{w}}+\sigma_{\mathrm{w}}$ imperfection are similar to that exhibited by the shell with the actual measured imperfection and are characterized by a 
localization of a single buckle near one end of the shell. In contrast, the shell with the $\mu_{\mathrm{w}}-\sigma_{\mathrm{w}}$ imperfection shape exhibits distributed initial buckling deformations shown in Fig 9c that are similar to those exhibited by the corresponding geometrically perfect shell. These results are significant because they suggest that the use of a mean imperfection shape and the corresponding standard deviation can bound the experimental buckling loads as well as predict physically meaningful response characteristics such as the buckling deformations. Results were also obtained for the two 8-ply orthotropic shells $\mathrm{C} 1$ and $\mathrm{C} 2$. In particular, buckling loads for the various imperfection shapes were calculated and are also presented in Table 1. Most notable, is the fact that the predicted buckling loads for the shells with the actual measured imperfection are bounded by the results for the shells with the $\mu_{\mathrm{w}}+\sigma_{\mathrm{w}}$ imperfection shape, and $\mu_{\mathrm{w}}-\sigma_{\mathrm{w}}$ imperfection shape. In addition, the experimental results agree well with the predicted results that include the effects of the actual measured geometric imperfection. The correlation would improve still further if other measured imperfections were included in the finite-element model; e.g., measured thickness variation, material property variation, and loading nonuniformities, as shown in Refs. 21 and 22. Specifically, the measured thickness imperfection has been shown to account for an additional 5-10\% reduction in the buckling load. In contrast, the results for shells with linear-bifurcation-mode imperfections are, for an imperfection amplitude equal to 0.5 times the nominal wall thickness, ultraconservative. Similarly, the lower-bound design recommendation given in NASA SP-8007 for the corresponding isotropic shell is equal to $\mathrm{P}_{\mathrm{cr}} / \mathrm{P}_{\mathrm{bif}}=0.47$, which is also ultraconservative, as expected.

\section{Response of Shells Subjected to Combined Axial Compression and Torsion}

A numerical study of the effects of the four different imperfection shapes on the buckling load of the 8-ply shells C1-C3 subjected to combined axial compression and torsion was also conducted. Normalized buckling interaction curves that include curves for a geometrically perfect shell, a shell with the actual measured imperfection, a shell with a $\mu_{\mathrm{w}}+\sigma_{\mathrm{w}}$ imperfection, a shell with a $\mu_{\mathrm{w}}-\sigma_{\mathrm{w}}$ imperfection, a shell with an linear-bifurcation-mode imperfection, and the corresponding NASA SP-8007 design curves are shown for shells C1-C3 in Figs. 10-12, respectively. The measured experimental buckling load for the compression loading is indicated on the figure by the solid circular symbol and is included for comparison. The buckling loads (stress resultants) $N_{x}$ and $N_{x y}$ are predicted from a geometrically nonlinear analysis, and are normalized with respect to the corresponding the linear bifurcation buckling loads $N_{x, \text { bif }}$, and $N_{x y, b i f}^{+}$of a geometrically perfect shell. The superscript "+" indicates results for a positive torsion load. A summary of linear bifurcation buckling loads for shells C1 through C3 is presented in Table 2.

The predicted results shown in Figs. 10 through 12 indicate that the buckling interaction curves for the geometrically perfect and imperfect shells are skewed with respect to the plane given by $N_{x y}=0$. The skewing is caused by the fact that the diagonal compression caused by the shear load is aligned with the outer 45-deg fibers for the case of negative shear and is perpendicular to the fibers for the case of positive shear. Thus, for a negative-shear load the shell is stiffer. In addition, the buckling interaction curves are concave and are highly dependent on the laminate stacking sequence. This behavior is similar to the buckling behavior of anisotropic plates that are subjected to combined compression and shear loads presented in Refs. 38 and 39. In contrast, the NASA SP-8007 design guideline assumes a linear relationship between the critical compression-buckling load and the torsion-buckling load. Moreover, the bilinear curve is symmetric about $N_{x y}=0$ because the results in NASA SP-8007 are for isotropic shells.

The results in Figs. 10 through 12 show that shells $\mathrm{C} 1$ through $\mathrm{C} 3$ are sensitive to the as-measured imperfections and the $\mu_{\mathrm{w}}+\sigma_{\mathrm{w}}$ imperfection when the shell is subjected to compression-dominated loading. However, as the torsion load increases, the predicted buckling loads exhibit significantly less imperfection sensitivity for these particular imperfection shapes. The regions of the buckling load interaction curves for which the imperfection sensitivity exists is strongly dependent on the laminate stacking 
sequence. For example, the buckling load interaction curves for shell $\mathrm{C} 1$ exhibit a relatively large region of imperfection sensitivity for normalized torsion loads $N_{x y} / N_{x y, b i f}^{+}$that ranges from -0.9 to 0.5 and normalized compression loads $N_{x} / N_{x, b i f}$ that range from 0.65 to 0.97 , as shown in Fig. 10. However, the regions of imperfection sensitivity in shells $\mathrm{C} 2$ and $\mathrm{C} 3$ are significantly smaller than that exhibited by shell $\mathrm{C} 1$, as shown in Figs. 11 and 12, respectively. In contrast, the results indicate that a shell with a linearbifurcation-mode imperfection exhibits a significant reduction in the buckling loads for all load cases. The large difference in the response trends is caused by a fundamental difference in the shape of the imperfections in the shell and how they couple with the initial buckling deformation response of the shell. Specifically, the linear-bifurcation-mode imperfection is similar in character to the initial buckling response in the shell and, thus, exhibits a very strong coupling with the initial buckling deformation of the shell. In contrast, the actual measured imperfection and the imperfection signature, with imperfection amplitudes as large as $w_{d} / t=1.92$, are primarily a long-wave imperfection and these imperfection shapes do not exhibit an artificial strong coupling with the buckling deformations in this shell; thus, the reduction in the buckling load imperfection sensitivity is much less pronounced. In general, the results for shells with linearbifurcation-mode imperfections are, for the relatively small value of the imperfection amplitude considered here, ultraconservative. Similarly, the lower-bound design recommendation obtained by using NASA SP-8007 for the corresponding isotropic shell is also ultraconservative, as expected, and misrepresent the behavioral trends.

Finally, it is important to point out that although no test data were obtained for a C3-type shell subjected to torsion or combined torsion and compression, it is expected that the results for the shell with the actual measured imperfection will be very accurate. This expectation is based on the fact that torsionloaded shells are not compression dominated like the corresponding compression-loaded shells and, as a result, will not exhibit as high of a degree of imperfection sensitivity.

\section{Design Implications}

The approach presented herein for developing shell-buckling design criteria appears to offer a means for obtaining preliminary-design estimates of buckling loads for laminated-composite cylindrical shells subjected to combined loads, without having to resort to extensive testing programs. In addition, this approach offers a relatively affordable alternative to relying on historical test data for shells that do not represent the configuration, material system, or fabrication process associated with the design of interest. This design-criteria-development approach could be used as a tool in the early stages of a design process to determine refined estimates of the buckling loads for the actual as-built shell structure under consideration. To insure success for problems of interest where refined design criteria are nonexistent, this approach should always be used with a selected number of carefully conducted tests that should be used to validate the finite-element analyses and provide confidence in the design results. The validation tests should be carefully conducted so that representative analysis results can be generated to correlate with test results. The provenience and pedigree of each test specimen should be determined or measured to assure that the appropriate shell-wall geometry and thickness distribution, material properties, and fabrication processspecific effects are included in the analysis used to develop the design criteria.

The design-criteria-development approach described herein has wider implications; that is, it can be used to generate buckling design curves for commonly used structural forms and material systems that account for manufacturing-process imperfections and provide reliable estimates of buckling resistance that are suitable for preliminary design. Design curves of this fidelity will essentially provide a scientificallybased replacement for the overly conservative empirical knockdown factors typically used in design today to account for imperfection sensitivity of shell structures. Once a database of manufacturing-process-specific imperfections is established by the technical community, a designer will be able to determine which 
various imperfections are representative of the manufacturing procedure or fabrication process that is appropriate for his or her design and then use the relevant design curves. This approach will enable industry to develop a given design without having to repeatedly pay for extensive development tests to develop design knockdown factors. In addition, the refined design criteria should yield substantial weight savings in a given design.

\section{Concluding Remarks}

A new analysis-based approach for developing shell-buckling design criteria for laminated-composite cylindrical shells made of graphite-epoxy material with a tape-laying process has been presented. This approach accounts for the effects of the actual measured initial geometric imperfections in a manner that is suitable for the development of preliminary design data for this class of shells. In particular, a characteristic manufacturing imperfection signature has been identified from the actual measured geometric imperfections for six laminated graphite-epoxy shells and the process used to synthesize the imperfection signature has been discussed in detail. More specifically, a "first-approximation" mean imperfection shape and the corresponding standard deviation of the imperfection shape were determined from the measured imperfection data for the six shells. Then, a "first-approximation" imperfection signature was used with high-fidelity nonlinear finite-element analyses to determine predictions of the buckling behavior of the three shells for uniaxial compression loading, torsion loading, and for combined uniaxial compression and torsion loading. Detailed comparisons of the analytical buckling predictions obtained by using the "firstapproximation" imperfection signature, by using the actual measured imperfection data, and by using a linear-bifurcation-mode imperfection shape, and with test results have been presented. Moreover, comparisons with the corresponding results obtained by extrapolating the lower-bound design data given in NASA SP 8007 to the laminated-composite shells have been presented. In addition, the high-fidelity nonlinear shell analysis procedure used to predict the buckling and nonlinear response of the shells has been described and response characteristics have been discussed.

The results presented herein indicate that the predicted buckling loads for the shells obtained by using the actual measured imperfection shapes in the finite-element analyses agree well the corresponding experimentally measured buckling loads for the compression-loaded shells, e.g., $10 \%$ maximum difference between predicted buckling loads with actual measured imperfection and the corresponding measured buckling loads. With regards to the "first-approximation" imperfection signature, the results show that, for the most part, the predicted buckling interaction curves for combined compression-torsion loadings that were obtained by using the actual measured imperfection shape fall within the corresponding interaction curves for plus or minus one standard deviation. In addition, comparisons of the nonlinear finite-element analyses show that the "first-approximation" imperfection signature yields response characteristics that are similar to those obtained by using the actual measured imperfection data in the analyses. These results are significant because one-standard-deviation bounds to the test data and the reproduction of significant nonlinear behavioral characteristics represent necessary conditions that should be met by a "firstapproximation" imperfection signature that is to be used to develop an analysis-based design criteria. In contrast, the results also show that buckling interaction curves obtained analytically by using a linearbifurcation-mode imperfection shape and the curves obtained by using the lower-bound experimental data in NASA SP 8007 are ultraconservative, compared to the corresponding results obtained analytically by using the actual measured imperfection data or the "first-approximation" imperfection signature. Overall, the results indicate that the analysis-based approach for developing reliable preliminary-design criteria that has been presented herein has the potential to provide improved, less conservative buckling-load estimates, and to reduce the weight and cost of developing buckling-resistant shell structures. 


\section{References}

1. Bushnell, D., Computerized Buckling Analysis of Shells, Kluwer Academic Publishers, Boston, 1989 (see also AFWAL-TR-81-3049, December, 1981, Wright-Patterson Air Force Base).

2. Singer, J., Árbocz, J., and Weller, T., Buckling Experiments: Experimental Methods in Buckling of Thin-Walled Structures, Vol. 2, John Wiley \& Sons, Inc., New York, 2002.

3. von Kármán, T. and Tsien, H. S., "The Buckling of Thin Cylindrical Shells Under Axial Compression," Journal of the Aeronautical Science, Vol. 8, No. 8, June 1941, pp. 303-312.

4. Donnell, L. H. and Wan, C. C., "Effect of Imperfections on Buckling of Thin Cylinders and Columns Under Axial Compression.," Journal of Applied Mechanics, Vol. 17, No. 1, March 1950, pp. 73-83.

5. Koiter, W. T., On the Stability of Elastic Equilibrium. (in Dutch), H. J. Paris, Amsterdam, Holland, 1945; translation available as AFFDL-TR-70-25, February, 1970, Wright-Patterson Air Force Base.

6. "Buckling of Thin-Walled Circular Cylinders," NASA Space Vehicle Design Criteria, NASA SP-8007, September 1965 (Revised 1968).

7. "Buckling of Thin-Walled Truncated Cones," NASA Space Vehicle Design Criteria, NASA SP-8019, September 1968.

8. "Buckling of Thin-Walled Doubly Curved Shells," NASA Space Vehicle Design Criteria, NASA SP-8032, August 1969.

9. Budiansky, B, "Theory of Buckling and Postbuckling Behavior of Elastic Structures," Advances in Applied Mechanics, Vol. 14, Academic Press, 1974, pp. 1-65.

10. Árbocz, J. and Hol, J. M. A. M., "ANILISA - Computational Module for Koiter's Imperfection Sensitivity Theory," Report LR-582, Delft University of Technology, Delft, 1989.

11. Khot, N. S. and Venkayya, V. B., "Effect of Fiber Orientation on Initial Postbuckling Behavior and Imperfection Sensitivity of Composite Cylindrical Shells," AFFDL-TR-70-125, Wright-Patterson Air Force Base, Ohio, December 1970.

12. Cohen, G. A. and Haftka, R. T., "Sensitivity of Buckling Loads of Anisotropic Shells of Revolution to Geometric Imperfections and Design Changes," Computers \& Structures, Vol. 31, No. 6, 1989, pp. 985-995.

13. Tennyson, R. C., "Buckling of Laminated Composite Cylinders: A Review," Composites, Vol. 6, No. 1, 1975, pp. 17-24.

14. Árbocz, J., Babcock, C. D., Jr., "The Effects of General Imperfections on the Buckling of Cylindrical Shells," Journal of Applied Mechanics, Vol. 36, No. 1, pp. 28-38, 1969.

15. Árbocz, J. and Williams, J. G., "Imperfection Surveys on a 10-ft-Diameter Shell Structure," AIAA Journal, Vol. 15, 1977, pp. 949-952.

16. Árbocz, J., Babcock, C. D., Jr., "Computerized Stability Analysis Using Measured geometric Imperfections," Proceedings of the $12^{\text {th }}$ Congress of the International Council of the Aeronautical Sciences, Munich, Germany, ICAS-80-20.0, pp. 688-701, 1980.

17. Árbocz, J., "The Imperfection Data Bank, a Means to Obtain Realistic Buckling Loads," Buckling of Shells- A State-of-the-Art Colloquium, E. Ramm, ed., Springer Verlag, Berlin, 1982, pp. 535-567.

18. "NASTRAN User's Manual," NASA-SP-222(08),Vol. 2, June, 1986.

19. Rankin, C. C., Brogan, F. A., Loden, W. A., and Cabiness, H. D., "STAGS Users Manual, Version 4.0," Lockheed Martin Missiles \& Space Co., Inc., Advanced Technology Center, Report LMSC P032594, 1999.

20. Starnes, J. H., Jr., Hilburger, M. W., and Nemeth, M. P., "The Effects of Initial Imperfections on the Buckling of Composite Cylindrical Shells," Composite Structures - Theory and Practice, P. Grant and C. Q. Rousseau, eds., ASTM STP 1383, 2000, pp. 529-550. 
21. Hilburger, M. H., and Starnes, J. H., Jr., "High-fidelity Analysis of Compression-loaded Composite Shells," Proceedings of the 42st AIAA/ASME/ASCE/AHS/ASC Structures, Structural Dynamics, and Materials Conference, Seattle, WA. AIAA Paper No. 2001-1394, 2001.

22. Hilburger, M.W., and Starnes, J. H., Jr., "Effects of Imperfections on the Buckling Response of Compressionloaded Composite Shells," International Journal of Non-linear Mechanics, Vol. 37, pp. 623-643, 2002.

23. Nemeth, M. P., Britt, V. O., Young, R. D., Collins, T. J., and Starnes, J. H., Jr., "Nonlinear Behavior of Space Shuttle Superlightweight Liquid-Oxygen Tank Under Prelaunch Loads," Journal of Spacecraft and Rockets, Vol. 36, No.6, November-December, 1999, pp. 788-803.

24. Nemeth, M. P., Young, R. D., Collins, T. J., and Starnes, J. H., Jr., "Nonlinear Behavior of Space Shuttle Superlightweight Liquid-Oxygen Tank Under End-of-Flight Loads," Journal of Spacecraft and Rockets, Vol. 36, No.6, November-December, 1999, pp. 828-835.

25. Young, R. D., Nemeth, M. P., Collins, T. J., and Starnes, J. H., Jr.,"Nonlinear Behavior of Space Shuttle Superlightweight Liquid-Oxygen Tank Under Booster Ascent Loads," Journal of Spacecraft and Rockets, Vol. 36, No.6, November-December, 1999, pp. 820-827.

26. Nemeth, M. P., Young, R. D., Collins, T. J., and Starnes, J. H., Jr., "Effects of Welding-Induced Imperfections on Behavior of Space Shuttle Superlightweight Liquid-Oxygen Tank," Journal of Spacecraft and Rockets, Vol. 36, No.6, November-December, 1999, pp. 812-819.

27. Nemeth, M. P., Young, R. D., Collins, T. J., and Starnes, J. H., Jr., "Effects of Initial Geometric Imperfections on the Nonlinear Response of the Space Shuttle Superlightweight Liquid-Oxygen Tank," International Journal of Non-Linear Mechanics, Vol. 37, No.4-5, June, 2002, pp. 723-744.

28. Nemeth, M. P. and Starnes, J. H., Jr., "The NASA Monographs on Shell Stability Design Recommendations - A Review and Suggested Improvements," NASA TP-1998-206290, January, 1998.

29. Árbocz, J. and Starnes, J. H., Jr., "Future Directions and Challenges in Shell Stability Analysis," Thin-Walled Structures, Vol. 40, 2002, pp. 729-754.

30. Chryssanthopoulos, M. K., Giavotto, V., and Poggi, C., "Statistical Imperfection Models for Buckling Analysis of Composite Shells," Buckling of Shell Structures, on Land, in the Sea and in the Air, J. F. Jullien, ed., Elsevier Applied Science Publishing Co., Inc., New York, 1991, pp. 43-52.

31. Claus, S. J., Manufacture-Structure-Performance Relationships for Filament-Wound Composite Shells, Ph. D. Dissertation, The Pennsylvania State University, 1994.

32. Árbocz, J. and Elishakoff, I., "Reliability of Axially Compressed Cylindrical Shells with General Nonsymmetric Imperfections," Journal of Applied Mechanics, Vol. 107, March, 1985, pp. 122-128.

33. Árbocz, J., Starnes, J. H., Hr., and Nemeth, M. P., "On the Accuracy of Probabilistic Buckling Load Predictions," Proceedings of the 4lst AIAA/ASME/ASCE/AHS/ASC Structures, Structural Dynamics, and Materials Conference, Atlanta, GA. AIAA Paper No. 2000-1236, 2000.

34. Riks, E., "Progress in Collapse Analysis," Journal of Pressure Vessel Technology, Vol. 109, 1987, pp. 27-41.

35. Park, K. C., "An Improved Stiffly Stable Method for Direct Integration of Nonlinear Structural Dynamics," Journal of Applied Mechanics, Vol. 42, June 1975, pp. 464-470.

36. Riks, E., Rankin, C. C., and Brogan, F. A., "On the Solution of Mode Jumping Phenomena in Thin-walled Shell Structures," Computer Methods in Applied Mechanics and Engineering, Vol. 136 (1-2), 1996, pp. 59-92.

37. Bushnell, D., "Static Collapse: A Survey of Methods and Modes of Behavior," Collapse Analysis of Structures, PVP-Vol. 84, ASME, 1984, pp. 30-32

38. Nemeth, M. P., "Buckling Behavior of Long Symmetrically Laminated Plates Subjected to Combined Loadings," NASA TP-3195, 1992.

39. Nemeth, M. P., "Buckling Behavior of Long Anisotropic Plates Subjected to Combined Loads," NASA TP-3568, 1995. 
Table 1: Numerically Predicted and Experimentally Measured Buckling Loads for Compression-loaded Shells.

\begin{tabular}{|c|c|c|c|c|c|c|c|}
\hline \multirow[b]{2}{*}{ Shell } & \multicolumn{6}{|c|}{ Predicted Buckling Loads, lbf } & \multirow[b]{2}{*}{$\begin{array}{c}\text { Experimental } \\
\text { Buckling } \\
\text { Load }\end{array}$} \\
\hline & $\begin{array}{c}\text { Perfect } \\
\text { Shell }\end{array}$ & $\begin{array}{c}\text { Measured } \\
\text { Imperfection }\end{array}$ & $\begin{array}{c}\text { Mean } \\
\text { Imperfection, } \\
\mu\end{array}$ & $\begin{array}{c}\mu+\sigma \\
\text { Imperfection }\end{array}$ & $\begin{array}{c}\mu-\sigma \\
\text { Imperfection }\end{array}$ & $\begin{array}{c}\text { Linear- } \\
\text { bifurcation- } \\
\text { mode } \\
\text { Imperfection, } \\
w_{o} / t_{\text {nom }}=0.5\end{array}$ & \\
\hline $\mathrm{C} 1$ & 29900 & 29300 & 29000 & 27500 & 29850 & 17040 & 27788 \\
\hline $\mathrm{C} 2$ & 36300 & 34400 & 36170 & 34430 & 36930 & 14470 & 31924 \\
\hline C3 & 41500 & 38180 & 39100 & 36400 & 40200 & 21300 & 34082 \\
\hline
\end{tabular}

Table 2: Numerically Predicted Linear Bifurcation Buckling Loads (Stress Resultants) for Geometrically Perfect 8ply Shells.

\begin{tabular}{ccc}
\hline Shell & $N_{x, \text { bif }}$, lbf/in & $N_{x, \text { bif }}$, lbf/in \\
\hline C1 & 592.4 & 205.0 \\
C2 & 729.4 & 186.3 \\
C3 & 847.2 & 193.4 \\
\hline
\end{tabular}




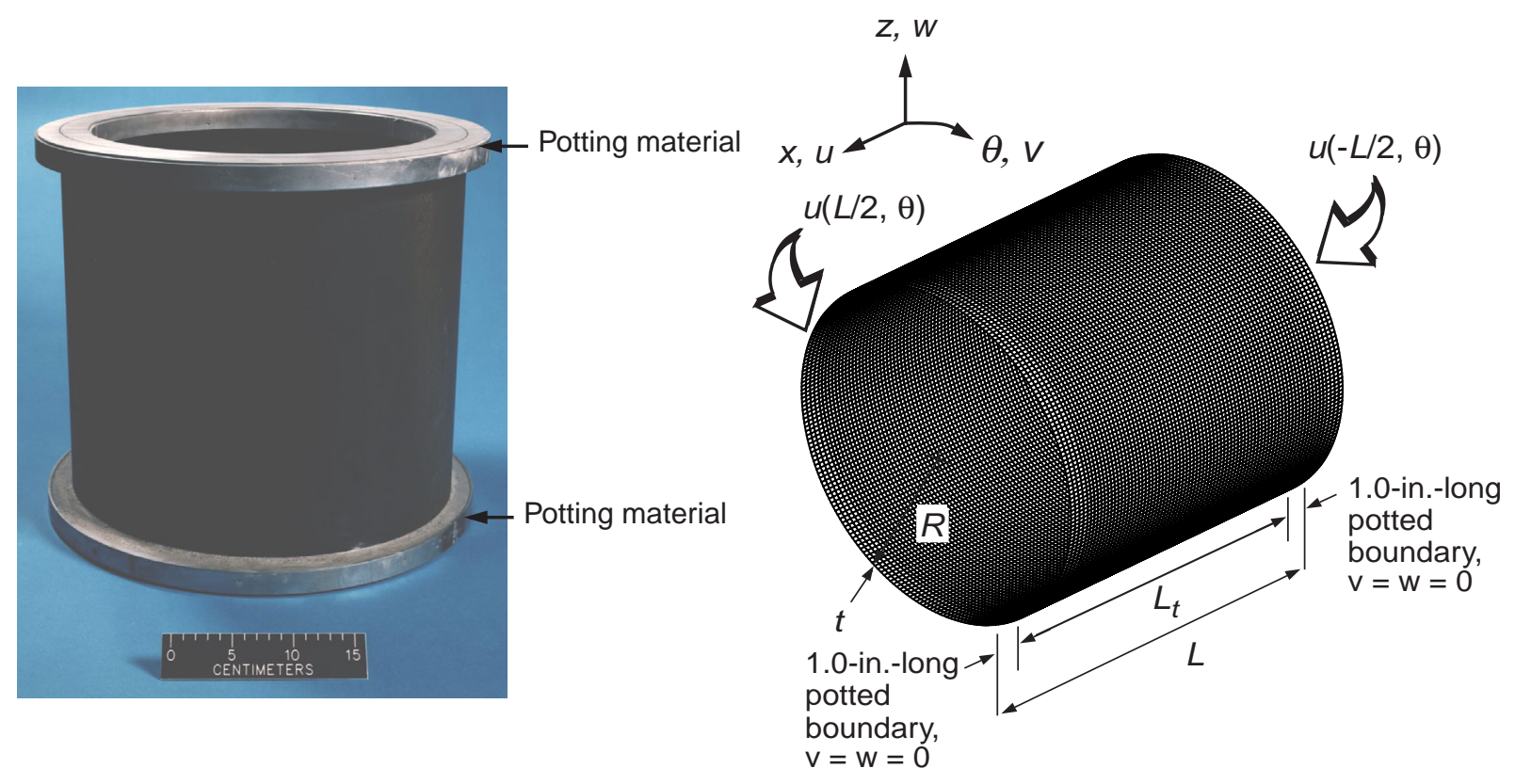

Fig. 1 Typical specimen and finite-element model geometry and boundary conditions.

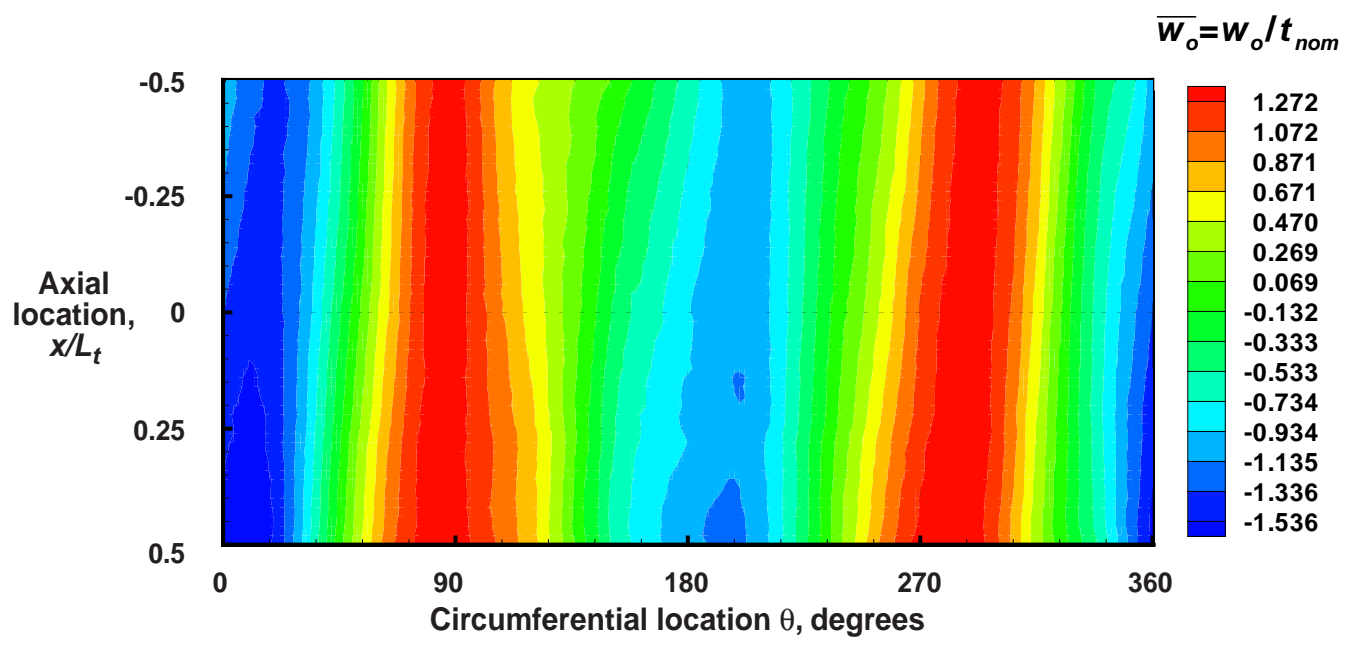

Fig. 2 Typical measured inner-surface imperfection shape for shell specimen C3. 

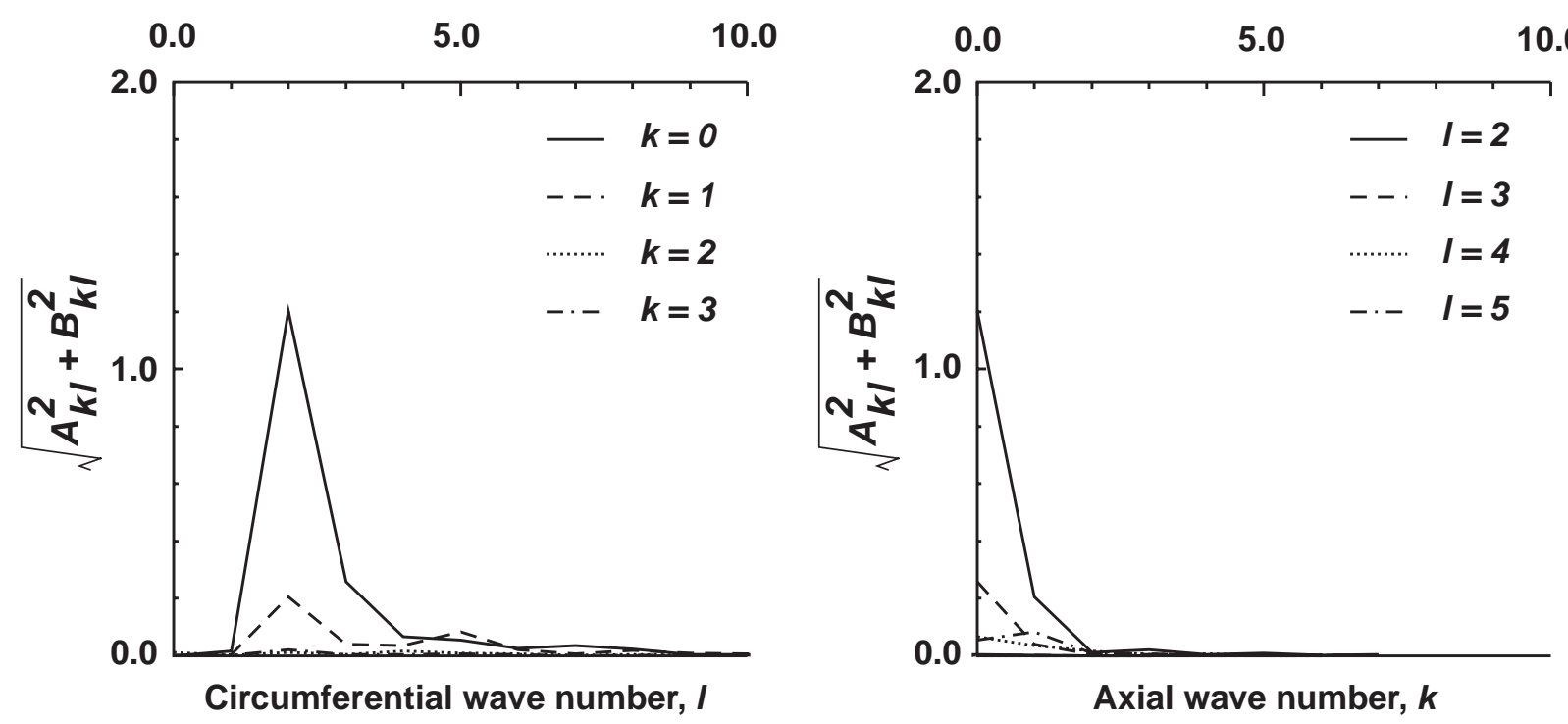

Fig. 3 Coefficient distribution of a Fourier series representation of the measured imperfection shape for shell specimen $\mathrm{C} 3$.

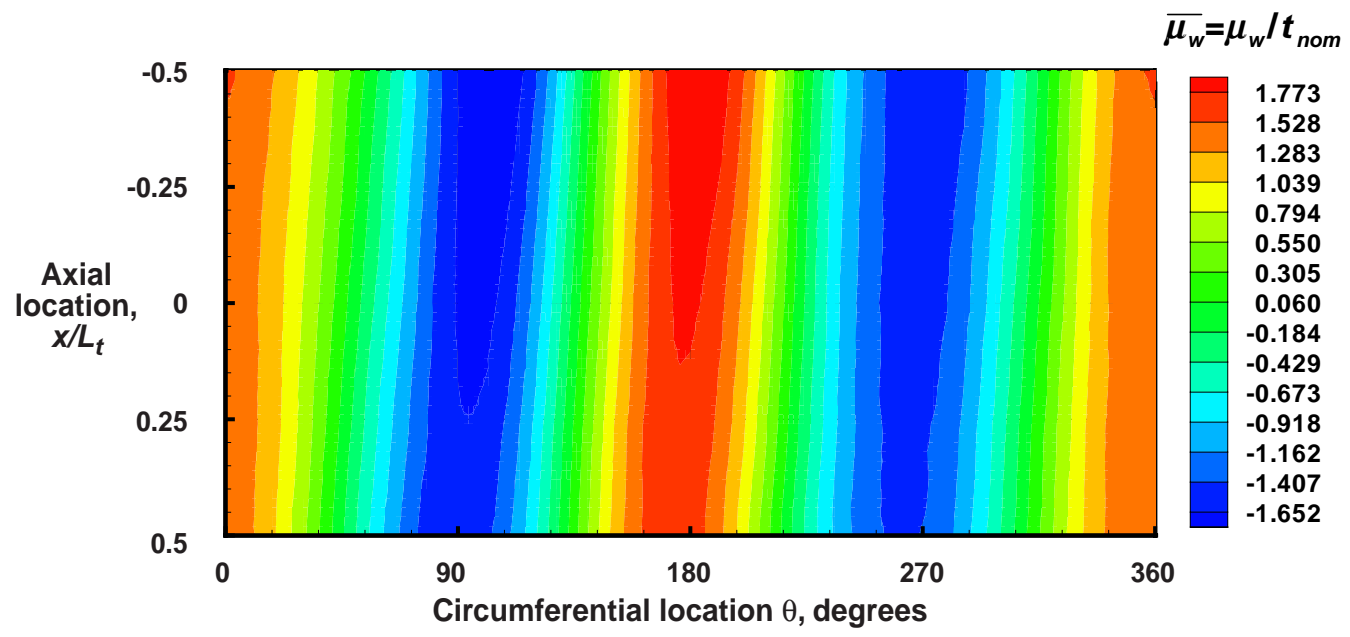

Fig. 4 Calculated "first-approximation" mean imperfection signature. 


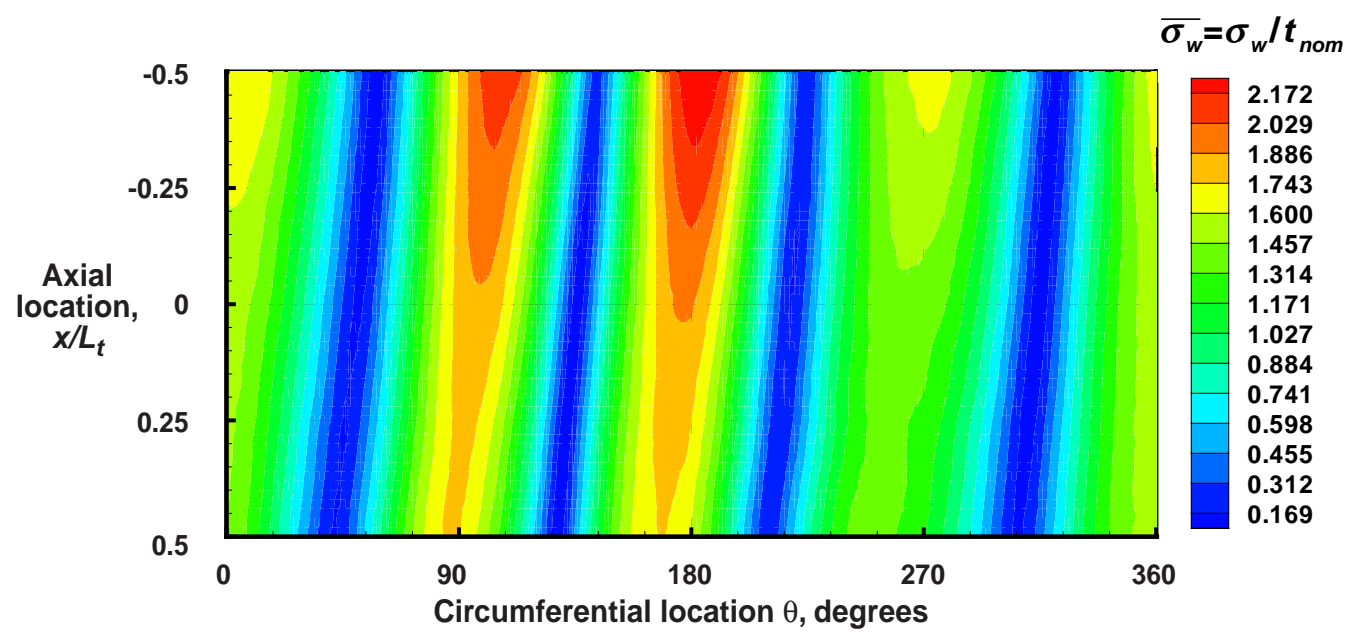

Fig. 5 Calculated standard deviation to the imperfection signature shown in Fig. 4.

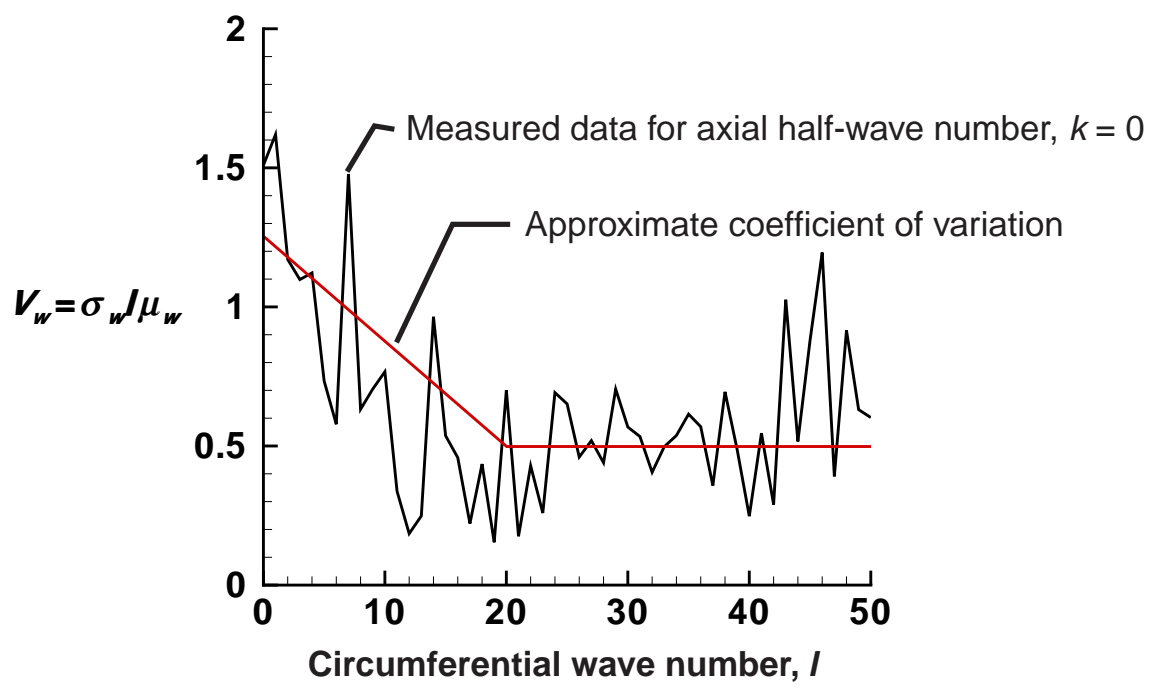

Fig. 6 Coefficient of variation for the axial half-wave number $k=0$ as a function of circumferential wave number $l$. 


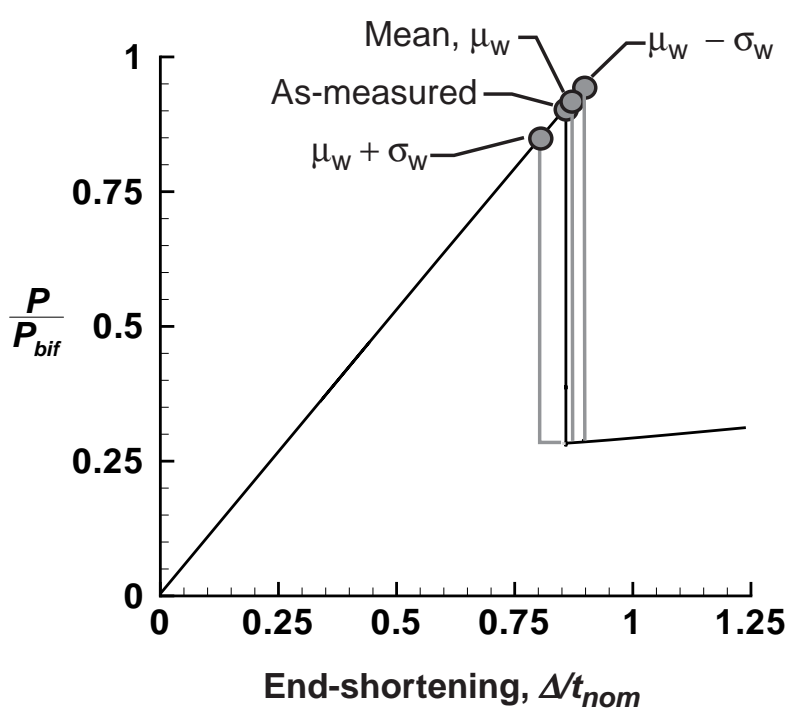

a) Predicted load-end-shortening response curves for shell C3 with selected imperfections.

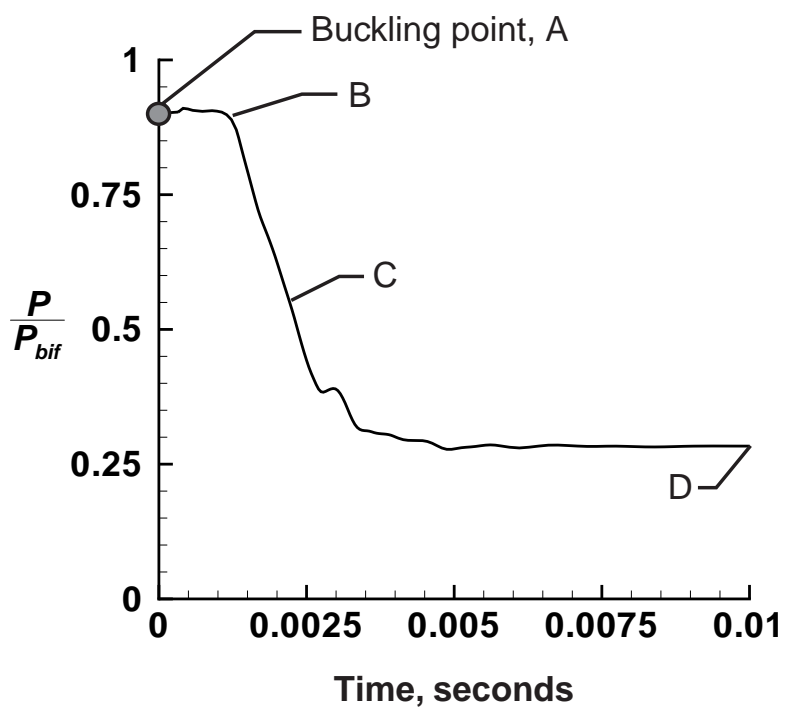

b) Predicted load-time history during collapse for shell C3 with the actual measured imperfection.

Fig. 7 Predicted nonlinear response for the compression-loaded quasi-isotropic shell C3 with various imperfection shapes.

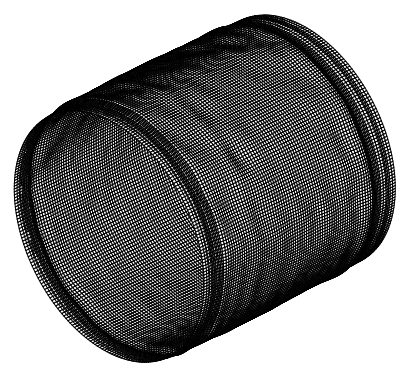

a) Prebuckling deformations b) Initial buckling Time $=0.0$ seconds $\mathrm{P} / \mathrm{P}_{\mathrm{cr}}=0.896$

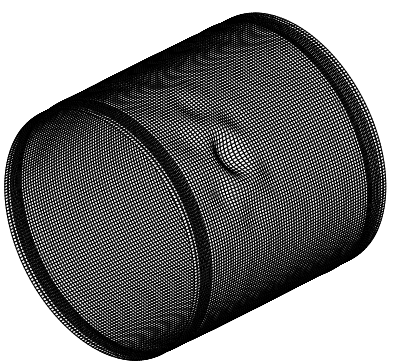
deformations Time $=0.0012$ seconds $\mathrm{P} / \mathrm{P}_{\mathrm{cr}}=0.890$

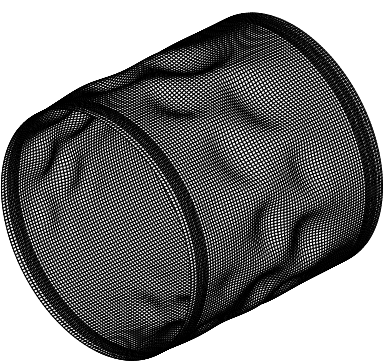

c) Transient buckling deformations

Time $=0.0024$ seconds $\mathrm{P} / \mathrm{P}_{\mathrm{cr}}=0.554$

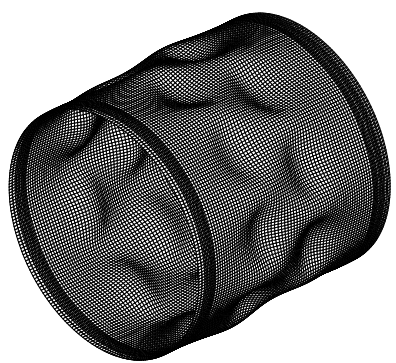

d) Initial post-buckling deformations Time $=0.01$ seconds $\mathrm{P} / \mathrm{P}_{\mathrm{cr}}=0.311$

Fig. 8 Predicted buckling deformation response for shell C3 with the actual measured initial imperfection. 


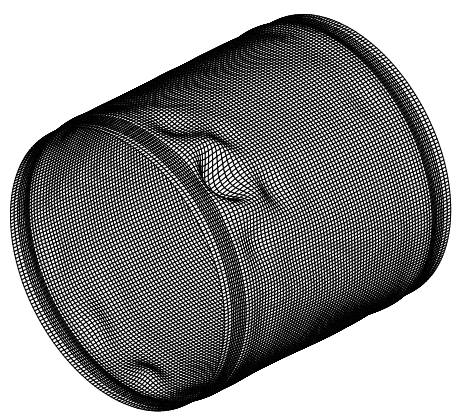

a) Mean imperfection, $\mu_{w}$ Time $=0.0011$ seconds $\mathrm{P} / \mathrm{P}_{\mathrm{cr}}=0.918$

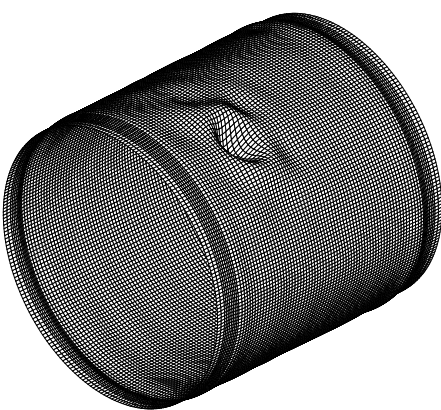

b) $\mu_{\mathrm{w}}+\sigma_{\mathrm{w}}$ imperfection Time $=0.0012$ seconds $\mathrm{P} / \mathrm{P}_{\mathrm{cr}}=0.855$

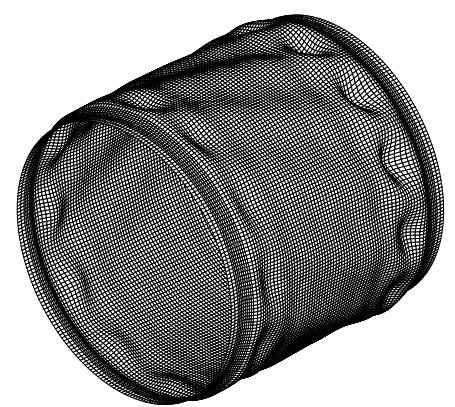

c) $\mu_{\mathrm{w}}-\sigma_{\mathrm{w}}$ imperfection Time $=0.0010$ seconds $\mathrm{P} / \mathrm{P}_{\mathrm{cr}}=0.943$

Fig. 9 Typical initial buckling deformation responses for shell C3 with selected simulated initial imperfections.

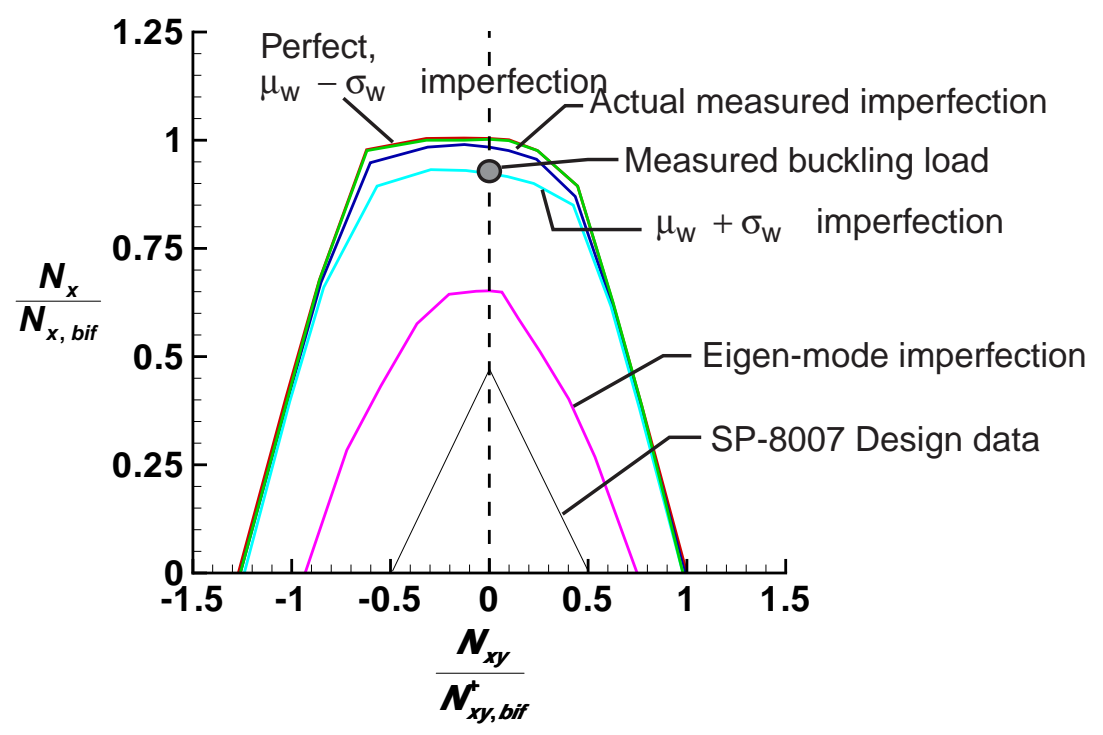

Fig. 10 Predicted buckling interaction curves for the axially stiff orthotropic shell C1 subjected to combined axial compression and torsion. 


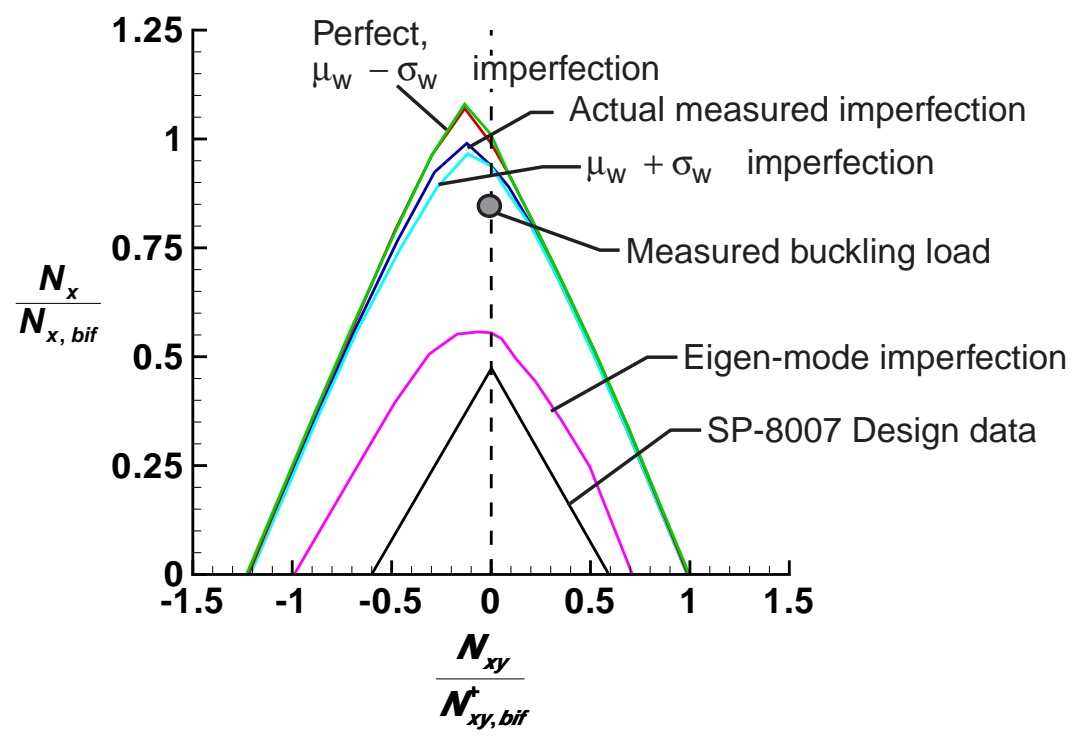

Fig. 11 Predicted buckling interaction curves for the circumferentially stiff orthotropic shell C2 subjected to combined axial compression and torsion.

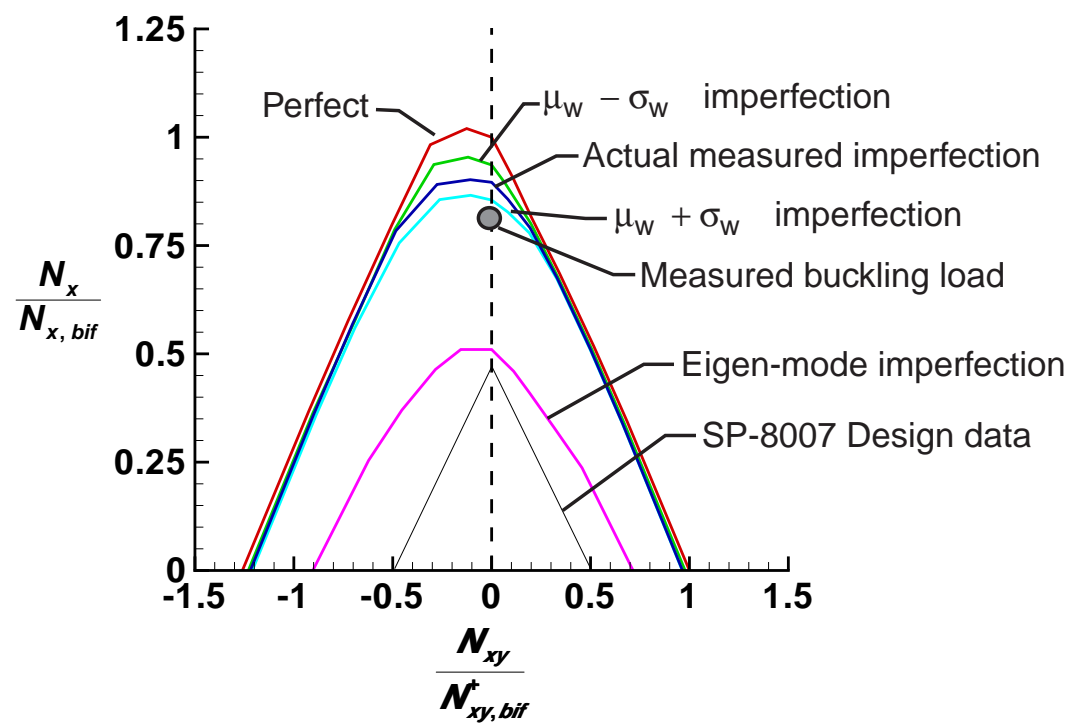

Fig. 12 Predicted buckling interaction curves for the quasi-isotropic shell C3 subjected to combined axial compression and torsion. 


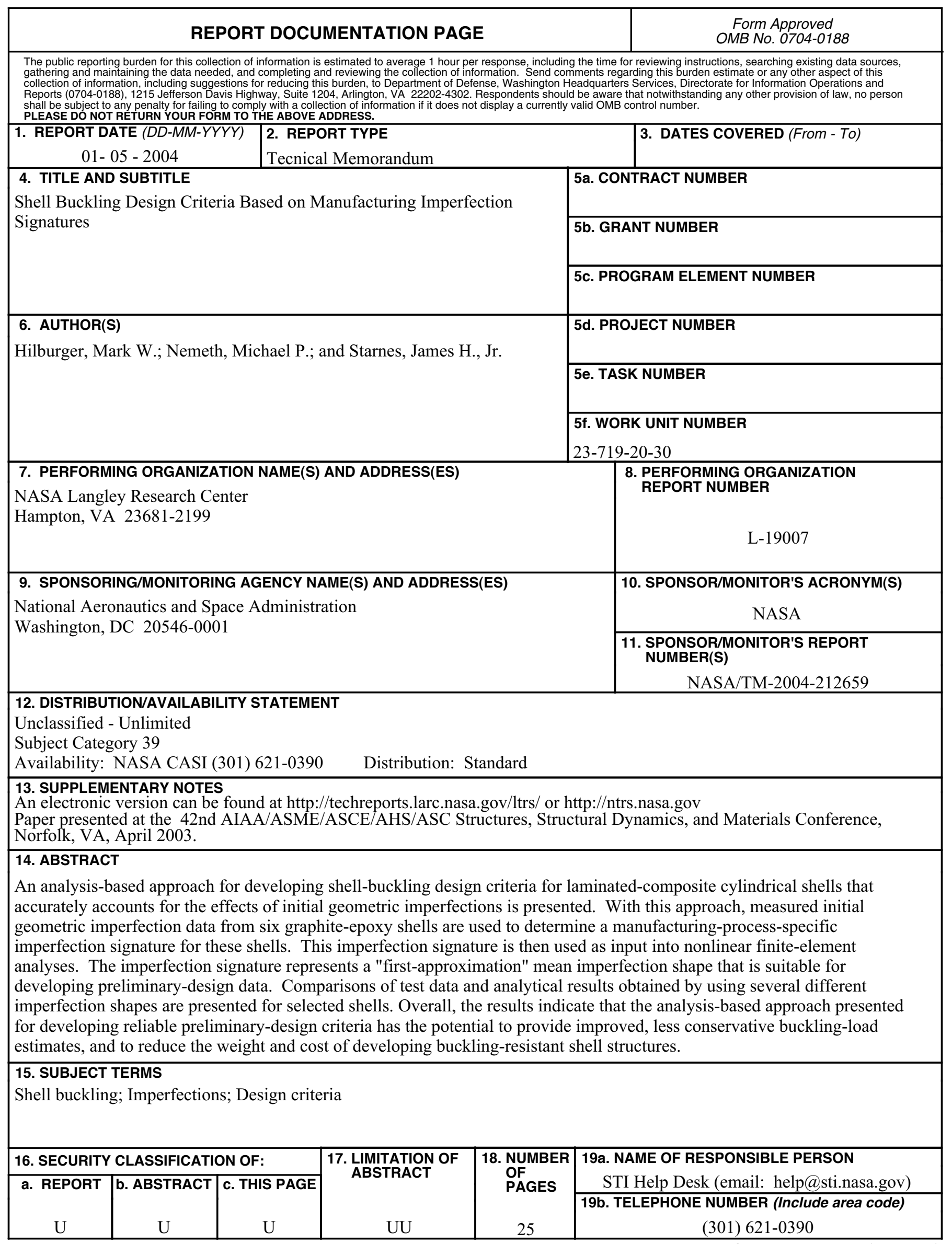

